\title{
CARDIOVASCULAR ASPECTS OF AUTONOMIC DYSREFLEXIA SINCE GUTTMANN AND WHITTERIDGE (1947)
}

\author{
By H. L. Frankel, M.B., F.R.C.P. ${ }^{1}$ and C. J. Mathias, D.Phil., M.R.C.P. ${ }^{2}$ \\ ${ }^{1}$ National Spinal Injuries Centre, Stoke Mandeville Hospital, Aylesbury, and \\ ${ }^{2}$ Wessex Regional Renal Unit, Southampton University Department of \\ Renal Medicine, St Mary's Hospital, Portsmouth, U.K.
}

Key word: Dysreflexia.

'AUTONOMIC DYSREFLEXIA' in patients with high spinal cord lesions has been used in reference to the changes induced by a variety of stimuli which occur in target organs supplied by the sympathetic and parasympathetic nervous systems. The earliest description of the symptoms of autonomic dysreflexia which we have been able to find is by Hilton (I860) who described a 2I-year-old man with a tetraplegia complete below $\mathrm{C}_{5}$ segment whose 'bowels (did) not open without medicine (senna). On some days he has peculiar sensations of chilliness, becoming pale, then feels hot and flushed both at defaecation and micturition. The more constipated the bowel, the more these peculiar sensations are experienced.' Hilton described these phenomena but drew no conclusion.

It was during World War I that Head and Riddoch made detailed observations of autonomic dysreflexia in patients with spinal cord injuries. They accurately described the responses of sweat glands, genitalia, urinary bladder and rectum which were evoked by cutaneous stimulation below the level of the lesion and by injection of fluid into the bladder and the bowel (Head \& Riddoch, I917; Riddoch, I9I7). Riddoch (I9I7) also described the initial stage of spinal shock during which tendon reflexes could not be elicited and retention of urine and faeces occurred. This stage was followed by the second stage of reflex activity when stimulation of the skin produced sweating around and above the segmental level of the lesion, evacuation of the bladder and rectum and erection of the penis and seminal emissionimportant components of the 'mass reflex'.

In recently injured patients with high spinal cord injuries who are in spinal shock there is minimal cardiovascular reflex activity presumably because both the parasympathetic and sympathetic pathways in the isolated spinal cord are depressed (Mathias et al., 1977, I979a). Pronounced cardiovascular changes, however, occur when spinal cord reflex activity returns. These were classically described by Guttmann and Whitteridge (1947) in patients with lesions at or above the level of $\mathrm{T} 5$ during distension of the urinary bladder. They reported marked hypertension, a decrease in pulse rate, change of rhythm on the electrocardiograph (in particular extrasystoles), vasodilatation of the face, neck and nasal mucosa and vasoconstriction of fingers and toes. The patients complained of flushing and sweating of the face and neck, blockage of nasal air passages and headache. The authors thought these were important alarm symptoms of visceral activity in parts of the paralysed body. Since then there have been numerous reports which have confirmed Guttmann and Whitteridge's pioneering observations on the cardiovascular changes occurring during autonomic dysreflexia in patients with high thoracic and cervical spinal cord lesions. Similar changes also occur during cutaneous stimulation 
(Corbett et al., I971 $a$ ), defaecation and distension of the rectum (Pollock et al., I95I), spontaneous and induced muscle spasm (Corbett et al., I97I $b$ ), administration of intrathecal neostigmine and electrical stimulation for the collection of semen for artificial insemination (Guttmann \& Walsh, I97I; Rossier et al., I97I; Frankel et al., 1974), and labour (Guttmann, I963; Guttmann et al., 1965; Goller \& Paeslack, I970).

Studies of the haemodynamic changes occurring during autonomic dysreflexia have been continued at Stoke Mandeville Hospital by pupils of Sir Ludwig Guttmann (Corbett et al., I971 $a$, I97I $b$, I97Ic) and confirm that severe hypertension and marked bradycardia are outstanding features. There is venoconstriction and a decrease in calf and hand blood flow (Fig. I). Cardiac output, stroke volume, systemic vascular resistance and pulmonary arterial pressure increase (Corbett et al., 1975). These changes are thought to be the result of uninhibited

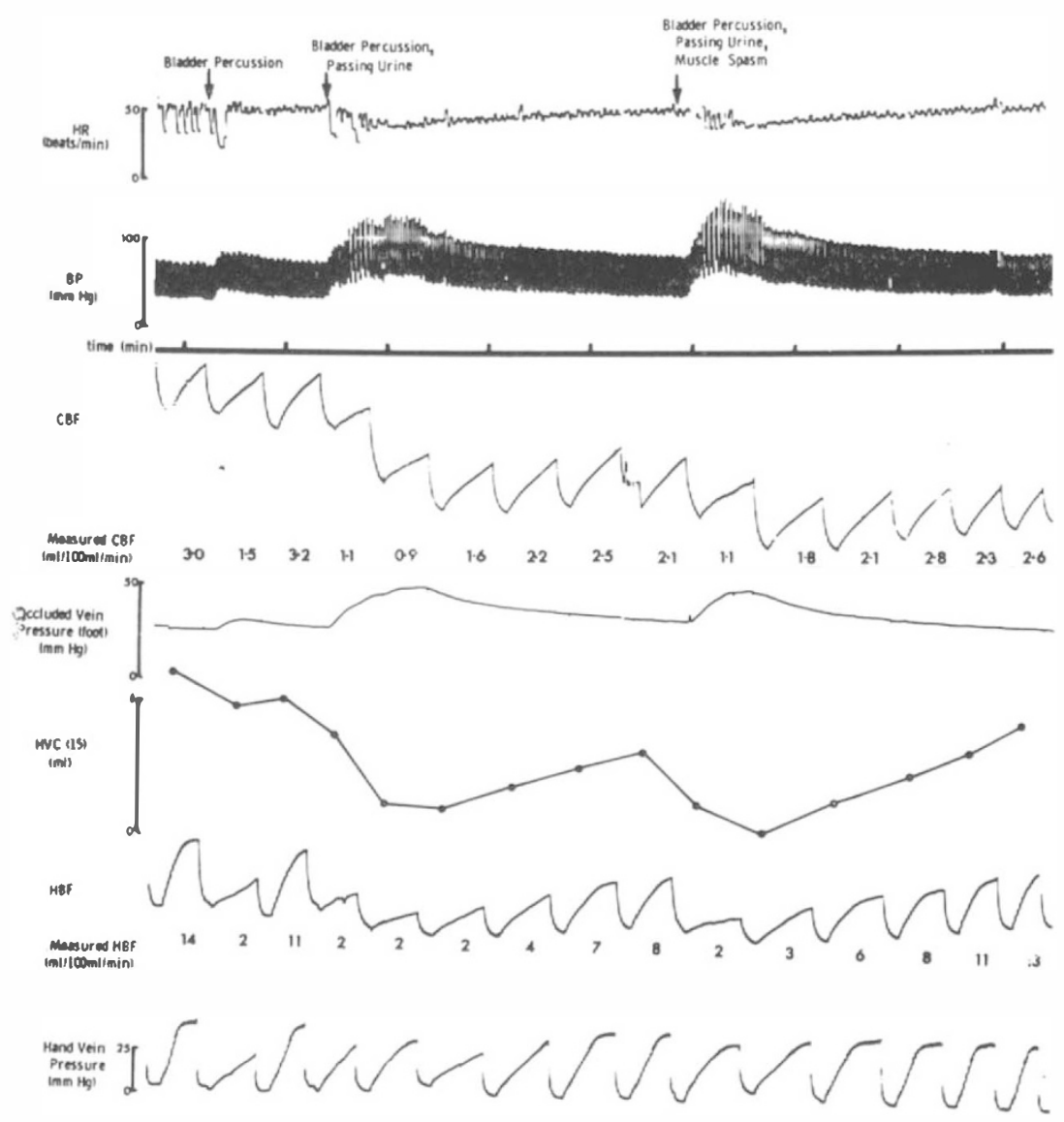

FIG. I

Effects of stimulating the urinary bladder by percussion of the anterior abdominal wall in a tetraplegic patient. The effects on heart rate (HR), blood pressure (BP), calf blood flow (CBF) pressure in an occluded vein in the foot, hand volume changes (HVC), hand blood flow $(\mathrm{HBF})$ and hand vein pressure are seen during bladder percussion alone; bladder percussion and the passage of urine; and bladder percussion, passage of urine and muscle spasm (Corbett et al., I97Ic).

$\mathrm{I} 7 / \mathrm{I}-\mathrm{D}$ 

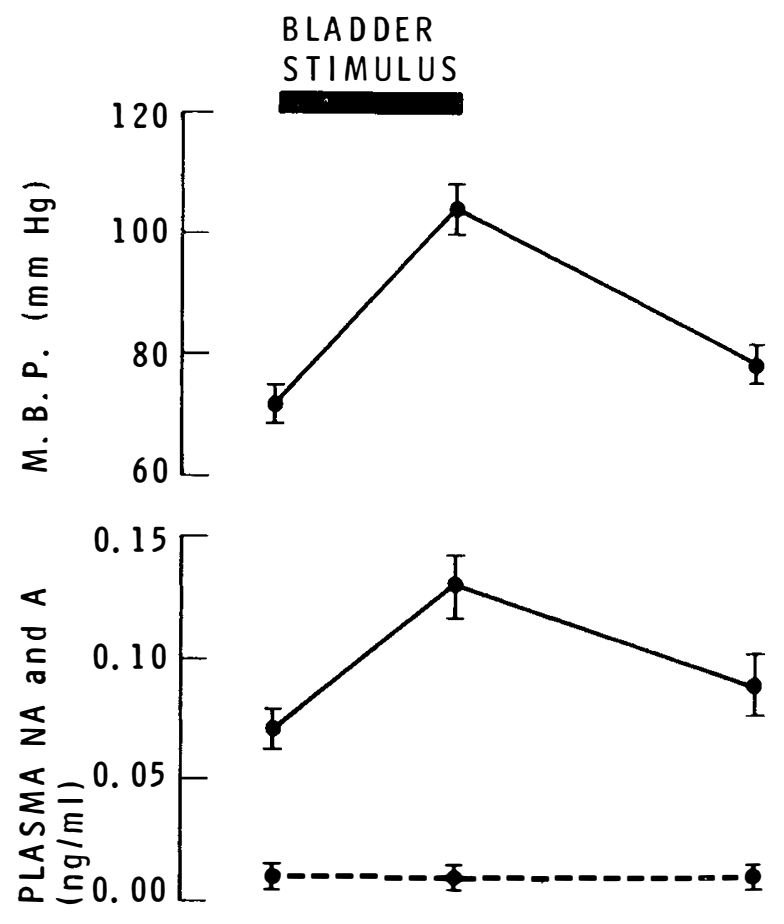

TIME (min)

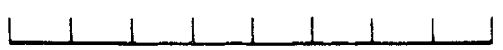

FIG. 2

Effects of stimulation of the urinary bladder on mean blood pressure (MBP) and levels of plasma noradrenaline (NA, continuous line) and adrenaline (A, interrupted line) in a group of tetraplegic patients.

sympathetic reflex activity working via the isolated spinal cord. In I947 Guttmann and Whitteridge wondered whether the release of adrenaline caused the phenomena they observed. Sensitive techniques for catecholamine measurement indicated that the hypertension during bladder contraction and muscle spasm is accompanied by a rise in levels of plasma noradrenaline but not plasma adrenaline (Fig. 2) (Mathias et al., 1976a). Noradrenaline is the neurotransmitter at sympathetic adrenergic nerve terminals, while adrenaline is the principal secretion from the adrenal medulla (Von-Euler, 1954). The rise in noradrenaline therefore probably reflects an increase in sympathetic nervous activity. This is also supported by studies which show a rise in dopamine-beta-hydroxylase (Fig. 3) (Frankel et al., I975; Mathias et al., 1976c), the enzyme proportionally released with noradrenaline when sympathetic nerve endings are stimulated (Weinshilboum et al., 197I). Plasma renin activity does not rise during such stimulation (Mathias et al., 1979b) and the overall evidence therefore is consistent with the view that the cardiovascular changes are the result of sympathetic nervous activity and are not secondary to the release of vasopressor hormones. In patients with high spinal cord lesions the afferent components of the baroreflex arc (the vagus and glossopharyngeal nerves) and the vagal efferent component are intact. Bradycardia appears to be a response to the hypertension and is probably mediated by the vagal efferent nerves. 


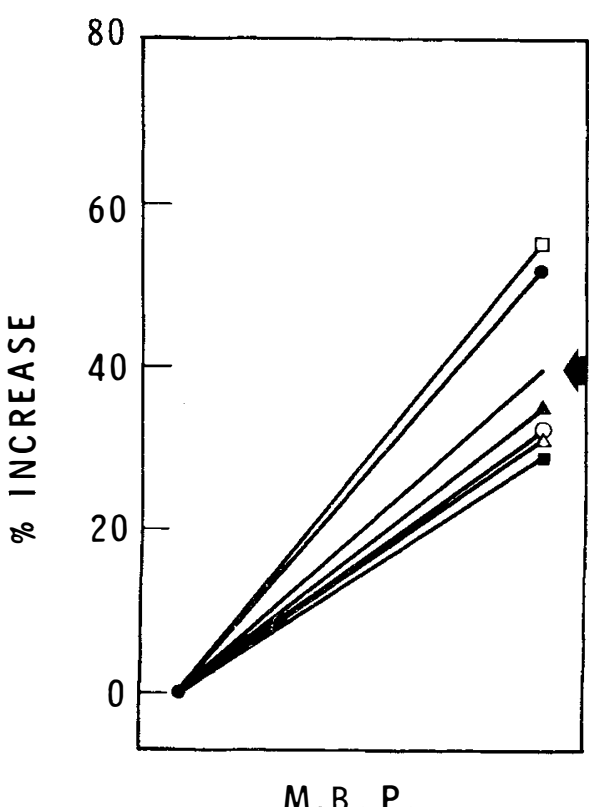

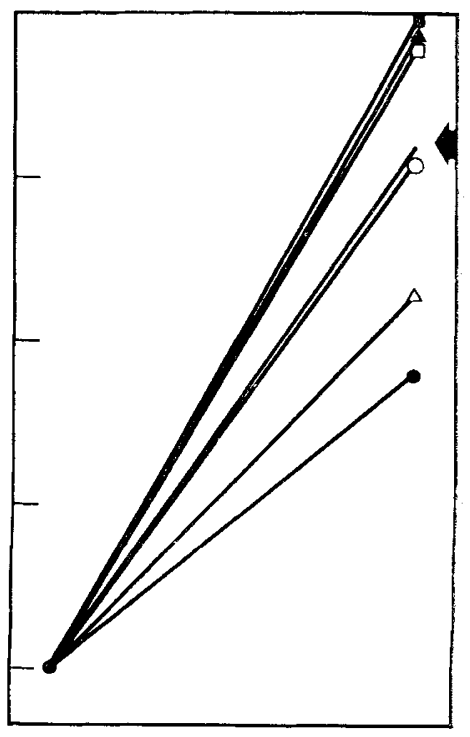

PLASMA D- $\beta-H$

FIG. 3

Percentage increase in mean blood pressure (MBP) and plasma dopamine-beta-hydroxylase $(\mathrm{DBH})$ in six tetraplegic subjects during bladder stimulation. The arrow indicates the mean level.

We have used the term autonomic dysreflexia rather than autonomic hyperreflexia because we feel that the latter narrows our thinking on the pathophysiological mechanisms involved. Although there is substantial evidence to indicate exaggerated spinal autonomic reflexes it seems likely that the absence of inhibitory supra-spinal influences is important. There is also evidence suggesting the existence of vasodilatory pathways (Folkow \& Rubenstein, I965; Kristt, I975; Reis et al., 1975), the absence of which may be yet another contributing factor. Studies using infusions of noradrenaline (Mathias et al., I976b) lend some support to these observations. The inadequacy of blood pressure correcting reflexes may explain why the cardiovascular components of autonomic dysreflexia occur in patients with. higher spinal cord lesions but not in those patients with lower spinal cord lesions.

We therefore believe that severe autonomic dysreflexia represents a 'sympathetic storm' which is uncorrected by control from higher centres. It is interesting to speculate on the role of viscero-spinal and somato-spinal reflexes in intact man as these are the reflexes which have been unmasked by the high spinal cord lesion. It is easy to see the advantages of a raised blood pressure and of increased cardiac output during skeletal muscle activity and these reflexes probably play an important role in maintaining blood pressure particularly as man needs an intricate reflex system to help maintain circulatory homeostasis during assumption of the erect posture. An impairment of these reflexes may, for instance, result in micturition syncope which is still an inadequately explained phenomenon. Autonomic dysreflexia is particularly initiated by distension of hollow viscera and it may play some part in maintaining adequate perfusion of these viscera when they are subjected to high intraluminal pressures. 
Further research needs to be done into the nature of these reflexes in both normal man and patients with spinal cord lesions. Further knowledge will be helpful in the management of hypertensive crises in these patients as fatalities have been reported (Jung \& Schmidt, I962; Guttmann \& Walsh, I97I). Hypertension in experimental animals, even for short periods of time, has been shown to damage blood vessels (Goldby \& Beilen, 1972). The hypertensive episodes associated with autonomic dysreflexia contribute to the mortality and morbidity of patients with high spinal cord lesions (Thompson \& Witham, I948); it is not uncommon for fits to occur during such episodes and we have seen several patients develop hemiplegia. The management of paroxysmal hypertension is difficult because drugs such as ganglion blockers, sympatholytic agents and peripheral vasodilators may lower already subnormal resting blood pressure and may dangerously potentiate hypotension during orthostasis. The levels of plasma prostaglandin $\mathrm{E}$ have been shown to rise during autonomic dysreflexia (Frankel et al., I974; Mathias et al., I975); this release of prostaglandin E probably moderates the hypertension and we have used infusion of prostaglandin $\mathrm{E}$ to control the hypertension associated with artificially provoked ejaculation and bladder filling. Clonidine effectively prevents hypertension during visceral stimulation in tetraplegic man (Mathias et al., I979c) and has the advantage of not lowering the resting blood pressure (Reid et al., I977).

In spite of more detailed knowledge of the mechanisms involved in autonomic dysreflexia and the newer drugs available to us it still remains most important to heed the warning of Guttmann and Whitteridge (1947) that autonomic dysreflexia is an important alarm symptom of visceral disturbance. Whenever possible the precipitating cause should be located and promptly treated, where such therapy is not immediately effective in abolishing the autonomic dysreflexia some of the drugs mentioned above should be used in addition.

\section{REFERENCES}

Corbett, J. L., Debarge, O., Frankel, H. L. \& Mathias, C. J. (1975). Cardiovascular responses in tetraplegic man to muscle spasm, bladder percussion and head-up tilt. Clinical and Experimental Pharmacology and Physiology, Supplement 2, I89-193.

Corbett, J. L., Frankel, H. L. \& HARRIS, P. J. (I97I $a$ ). Cardiovascular reflex responses to cutaneous and visceral stimuli in spinal man. Fournal of Physiology (London), 215, 395-409.

Corbett, J. L., Frankel, H. L. \& Harris, P. J. (I971 $b$ ). Cardiovascular changes associated with skeletal muscle spasm in tetraplegic man. Fournal of Physiology (London), 215, $38 \mathrm{I}-393$.

Corbett, J. L., Frankel, H. L. \& Harris, P. J. (I97Ic). Cardiovascular reflexes in tetraplegia. Paraplegia, 9, II3-I I2.

Folkow, B. \& Rubenstein, E. H. (1965). Behavioural and autonomic patterns evoked by stimulation of the lateral hypothalamic area in the cat. Acta Physiologica Scandinavica, 65, 292-299.

Frankel, H. L., Mathias, C. J., Smith, A. D. \& Spalding, J. M. K. (I975). Release of dopamine-beta-hydroxylase during sympathetic nervous activity in tetraplegic man. Fournal of Physiology (London), 247, 38-40P.

Frankel, H. L., MAThias, C. J. \& WALSH, J. J. (I974). Blood pressure, plasma catecholamines and prostaglandins during artificial erection in a male tetraplegic. Paraplegia, I2, 205-2I I.

GoldBY, F. S. \& BeIlin, L. J. (1972). How an acute rise in arterial pressure damages arterioles. Cardiovascular Research, 6, 569-584.

Goller, H. \& PAESLACK, V. (I970). Our experiences about pregnancy and delivery of the paraplegic women. Paraplegia, 8, I6I-I70. 
Guttmann, L., Frankel, H. L. \& Paeslack, V. (1965). Cardiac irregularities during labour in paraplegic women. Paraplegia, 3, I44-I 5 I.

Guttmann, L. (1963). The paraplegic patient in pregnancy and labour. Proceedings of the Royal Society of Medicine, 56, 383-387.

Guttmann, L. \& Walsh, J. J. (I97I). Prostigmine assessment test of fertility in spinal man. Paraplegia, 9, 39-5I.

GuttmanN, L. \& Whitteridge, D. (1947). Effects of bladder distension on autonomic mechanisms after spinal cord injuries. Brain, 70, 36I-404.

HEAD, H. \& RIDDOCH, G. (I9I7). The autonomic bladder, excessive sweating and some other reflex conditions, in gross injuries of the spinal cord. Brain, 40, I88-263.

Hilton, J. (I860). A course of lectures in pain and the therapeutic influence of mechanical and physiological rest in accidents and surgical diseases. Lancet, October 27th., $401-404$.

Jung, H. \& Schmidt, K. (1962). Zur Geburt nach Querschnittslähmung. Zbl. Gynäk., 84, IIO5-IIII.

KRISTT, D. A. (I975). Diencephalic vasodepressor responses independent of heart rate changes. Life Sciences, 16, 395-402.

Mathias, C. J., Christensen, N. J., Corbett, J. L., Frankel, H. L. \& Spalding, J. M. K. (1976a). Plasma catecholamines during paroxysmal neurogenic hypertension in quadriplegic man. Circulation Research, 39, 204-208.

Mathias, C. J., Christensen, N. J., Frankel, H. L. \& Spalding, J. M. K. (1977). Neurocirculatory dysfunction in patients soon after cervical spinal cord transection. European fournal of Intensive Care Medicine, 3, 168.

Mathias, C. J., Christensen, N. J., Frankel, H. L. \& Spalding, J. M. K. (ig79a). Cardiovascular control in recently injured tetraplegics in spinal shock. Quarterly fournal of Medicine, in press.

Mathias, C. J., Frankel, H. L., Christensen, N. J. \& Spalding, J. M. K. (I976b). Enhanced pressor response to noradrenaline in patients with cervical spinal cord transection. Brain, 99, 757-770.

Mathias, C. J., Frankel, H. L. \& Peart, W. S. (I979b). Unpublished observations.

Mathias, C. J., Frankel, H. L., Wing, L. M. H. \& Reid, J. L. (I979c). Unpublished observations.

Mathias, C. J., Hillier, K., Frankel, H. L. \& Spalding, J. M. K. (I975). Plasma prostaglandin E during neurogenic hypertension in tetraplegic man. Clinical Science and Molecular Medicine, 49, 625-628.

Mathias, C. J., Smith, A. D., Frankel, H. L. \& Spalding, J. M. K. (I976c). Release of dopamine-beta-hydroxylase during hypertension from sympathetic overactivity in man. Cardiovascular Research, 10, I76-18I.

Pollock, L. J., Boshes, B., Chor, H., Finkelman, I., Arieff, A. J. \& Brown, M. (I95 I). Defects in regulatory mechanisms of autonomic function in injuries to spinal cord. fournal of Neurophysiology, 14, 85-93.

Reid, J. L., Wing, L. M. H., Mathias, C. J., Frankel, H. L. \& Neill, E. (1977). The central hypotensive effect of clonidine: Studies in tetraplegic subjects. Clinical Pharmacology and Therapeutics, 21, 375-381.

Reis, D. J., Nathan, M. A. \& Doba, N. (I975). Two specific brainstem systems which regulate the blood pressure. Clinical and Experimental Pharmacology and Physiology, 2, Suppl. 2, I 79-183.

RIDDOCH, G. (1917). The reflex functions of the completely divided spinal cord in man compared with those associated with less severe lesions. Brain, 40, 264-402.

Rossier, A. B., Ziegler, W. H., Duchosal, P. W. \& Meylan, J. (I97I). Sexual function and dysreflexia. Paraplegia, 9, 5I-59.

Thompson, C. E. \& Witham, A. C. (I948). Paroxysmal hypertension in spinal cord injuries. New England Medical fournal, 239, 291-294.

Von-Euler, S. E. (I954). Adrenaline and nor-adrenaline: distribution and action. Physiological Reviews, 6, I5-22.

Weinshilboum, R. M., Kvetnansky, R., Axelrod, J. \& Kopin, I. J. (I97I). Proportional release of nor-epinephrine and dopamine-beta-hydroxylase from sympathetic nerves. Science, 174, I349-I35I. 